\title{
SUPERSONIC ELECTRIC ARC SPRAYING OF CRITICAL PARTS OF ROLLING STOCK OF RAILWAY TRANSPORT*
}

\author{
V.N. KORZHIK ${ }^{1,2}$, N.P. LYUTIK ${ }^{2}$, A.A. CHAJKA ${ }^{2}$, V.I. TKACHUK ${ }^{2,3}$, I.D. GOS ${ }^{2}$ and Yu.A. NIKITYUK \\ ${ }^{1}$ Guangdong Welding Institute (Chinese-Ukrainian E.O. Paton Welding Institute) \\ 510650, Guangzhou, PRC. E-mail:vnkorzhyk@qq.com \\ ${ }^{2}$ E.O. Paton Electric Welding Institute, NASU \\ 11 Kazimir Malevich Str., 03680, Kiev, Ukraine. E-mail: office@paton.kiev.ua \\ Scientific and Production Center «PLAZER» \\ 10-A Filatova Str., 01042, Kiev, Ukraine. E-mail: plazer2010@metal.ua \\ ${ }^{4}$ Scientific-Production Company «VISP» \\ 23 Moskovsky Ave., 04655, Kiev, Ukraine. E-mail: vizp@i.ua
}

\begin{abstract}
Rise of efficiency of application of railway transport requires new technologies and materials for increase of their life, first of all of the critical parts of rolling stock. In this aspect one of the most perspective technologies is a supersonic electric arc spraying or supersonic air-gas electric arc metallizing. It allows eliminating the main disadvantages of a traditional electric arc spraying related with low quality of coating, namely, increased burning out of the alloying elements of wire metal being sprayed due to air jet effect, low adhesion strength of the coating with the base material. 12 Ref., 2 Tables, 8 Figures.
\end{abstract}

Ke y w or d s : supersonic electric arc spraying, railway transport, critical assembly units, coating properties, coating cohesion strength

An improved supersonic electric arc metallizing (EAM) torch PLAZER15-SA-EM of PLAZER15-SA unit [1-10], containing a torch with combustion chamber operating under positive pressure (Figure 1), was developed for realizing a technology of supersonic electric arc spraying. Such a supersonic metalliz-

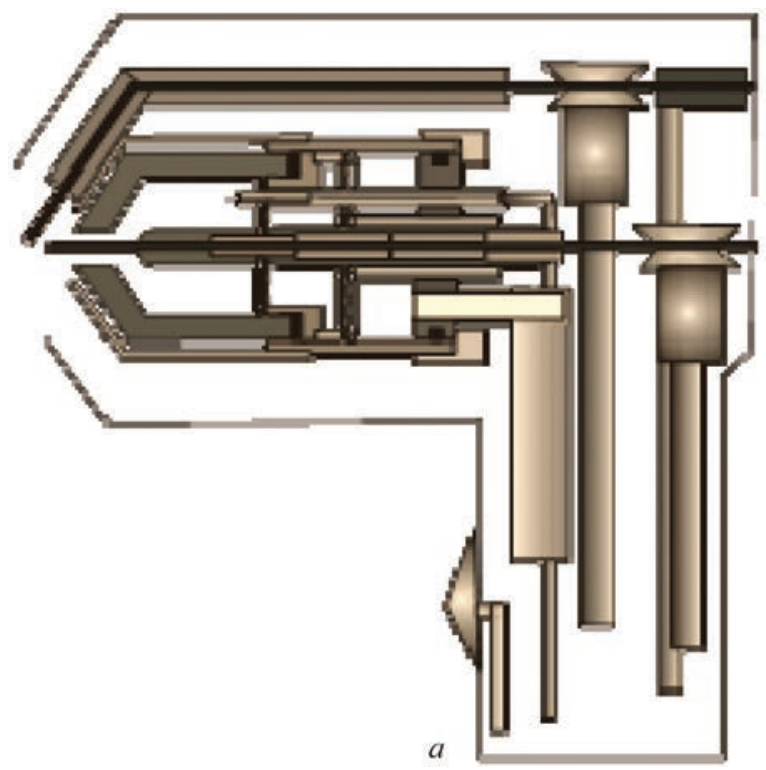

ing torch is based on a process, in which stabilized electric arc blowing is carried out by hot natural gas combustion products with supersonic velocity.

This is a hybrid technology combining an electric arc spraying with a supersonic flame spraying with formation of a single flow of supersonic high-temperature gas

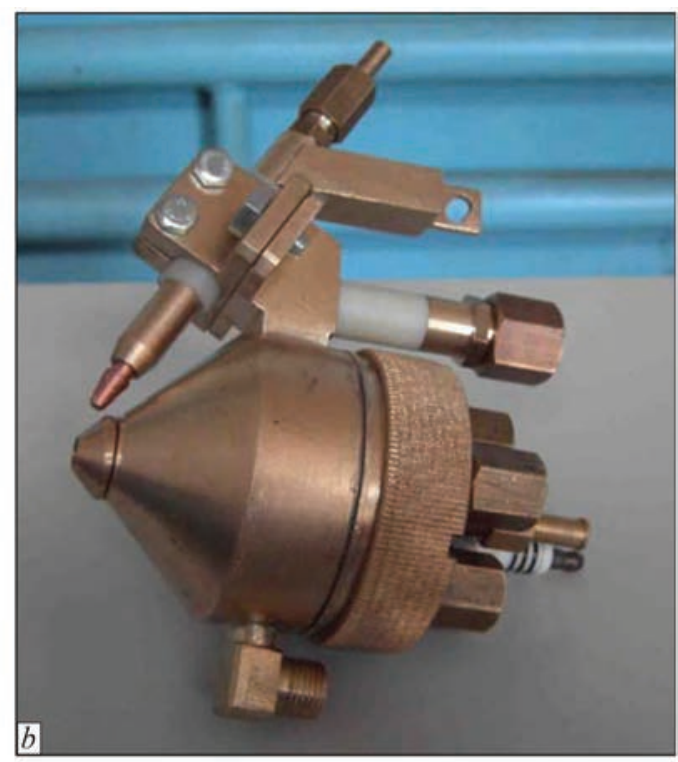

Figure 1. Scheme (a) and view $(b)$ of supersonic electric arc metallizing torch

\footnotetext{
"Based on materials of work made in scope of complex program of the NAS of Ukraine «Problems of service life and safety of structures, constructions and machines» (2013-2015).
} 

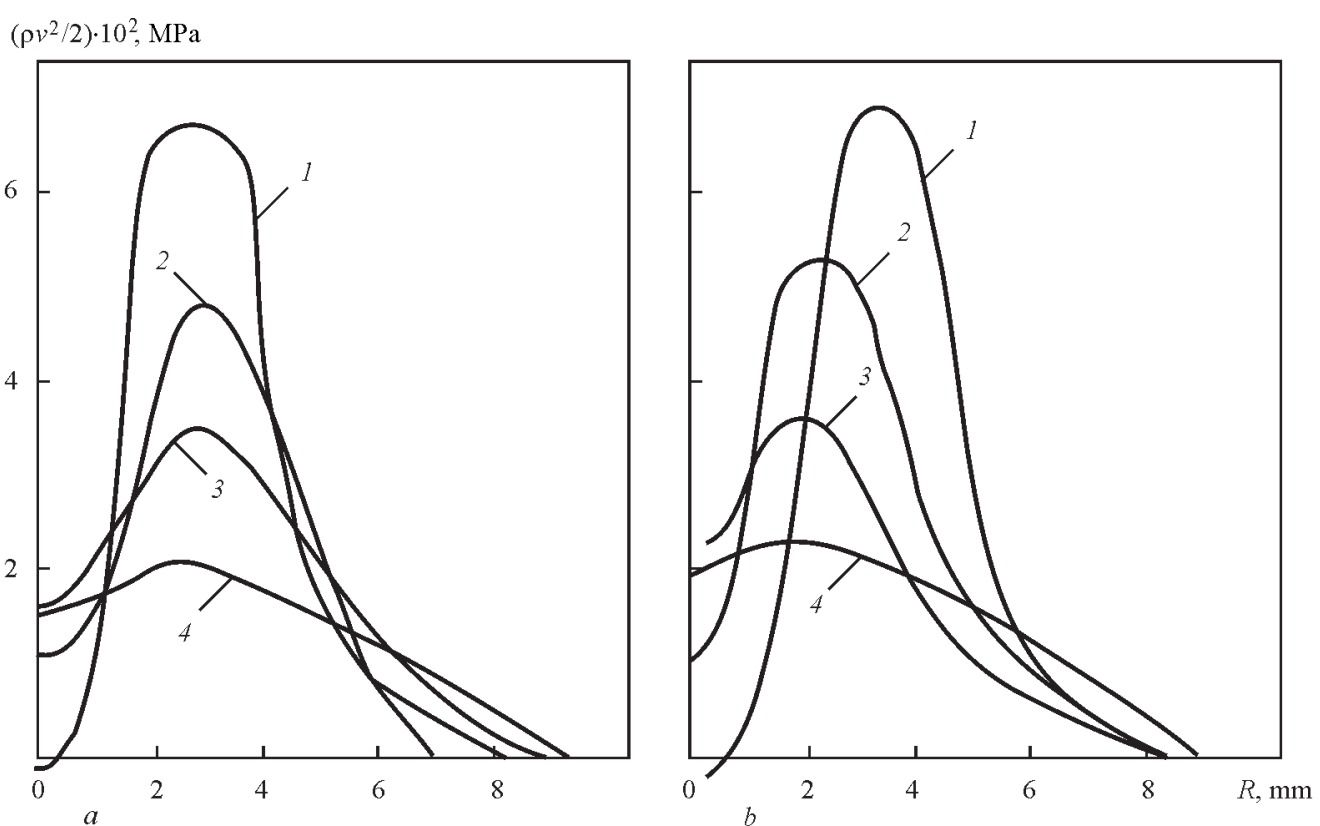

Figure 2. Profiles of dynamic pressing of supersonic metallizing torch at $\alpha=1.2(a)$ and $0.9(b)$ and distance from nozzle end: $1-2$; $2-7 ; 3-12 ; 4-22 \mathrm{~mm}$

and molten particles of wire material being sprayed. An electric arc is oriented along the high-temperature gas flow, velocity of which makes 1.5 Mach and burns between two consumable electrodes. Such a system provides for high level of arcing due to its orienting along the gas flow and, thus, a process of heat transfer into electrodes, i.e. intensive acceleration and refinement of molten metal particles, their resistance to in-flight oxidation, reduction of amount of evaporated material (due to formation of double-phase flow by supersonic jet of combustion product).

Indicated supersonic EAM torch for spraying the electric arc melted wires applies a weakly underexpanded supersonic jet of hot products of hydrocarbon gas combustion with air coming from sonic nozzle. The main disturbances in the flow are made by side wire. An area of air shadow is formed behind it down the jet. Figure 2 shows the radial changes of the velocity heads in jet cross section at 2.7, 12, $22 \mathrm{~mm}$ distance below the meeting point of side and central wires. Comparison of Figures 2, $a$ and 2, $b$ shows that a flow pattern is changed depending on mode of operation of the EAM torch in the supersonic flow with an obstacle in form of wire. The flow is focused behind the side wire if operated using enriched mixture, when excess air factor $\alpha=0.9$ (Figure 2, $b$ ) in contrast to diluted mixture with $\alpha \sim 1.2$ (Figure 2,a). Scattering of the dispersed particles in the supersonic flow is determined by a direction of vector of average velocity along a particle trajectory and turbulence parameters. Direction of the vector of average velocity (see Figure $2, b$ ) promotes constriction of metal flow, and at near-sonic velocity the level of turbulent fluctuations is reduced, the flow is laminated.
These two circumstances are decisive for reduction of scattering of dispersed phase, decreasing an expansion angle of metal flow and spread of particle velocities. Besides, a gas-dynamic situation (see Figure 2) formed behind the side electrode of the metallizing torch (see Figure 1) determines a nature of carrying, breaking of wire melt and dissipation of the dispersed phase. The metal jet stream takes place in the shadow zone of the side electrode equal 2.5-3.0 of calibers from nozzle edge. Further, aerodynamic breaking of the melt and acceleration of the dispersed particles take place downstream. It is particularly important using the flux-cored wires, when obtaining of the alloyed particles takes place at interaction of shell from low-carbon steel with flux core components. In this case alloying takes place during wire melting and melt jet stream.

Presence of a velocity component of blowing flow behind the side electrode, directed to jet axis (see Figure $2, b$ ), provides for constriction of metal flow, promoting reduction of dispersed phase dissipation. The expansion angle makes $7-10^{\circ}$.

It is known fact that one of the significant disadvantages of the coatings, produced using EAM, is a high level of their oxidation. This fact is usually considered as negative. The coatings being formed by oxidized particles are also characterized by high porosity and low coating to base cohesion strength. The main reason of material oxidation is its interaction with oxygen in zone of electric arc burning between the electrode wires.

The method for reduction of oxygen effect on molten metal is using the hydrocarbon gases (mostly methane) for oxygen «binding». For this the combustible 
Table 1. Modes of spraying the coating from flux-cored wires using different types of electric arc metallizing torches

\begin{tabular}{|l|c|c|c|c|c|c|}
\hline \multicolumn{1}{|c|}{ Type of electric arc equipment } & $\begin{array}{c}\text { Voltage, } \\
\mathrm{V}\end{array}$ & Current, A & $\begin{array}{c}\text { Air } \\
\text { consumption, } \\
\mathrm{m} / \mathrm{h}\end{array}$ & $\begin{array}{c}\text { Propane } \\
\text { consumption, } \\
\mathrm{m}^{3} / \mathrm{h}\end{array}$ & $\begin{array}{c}\text { Air } \\
\text { pressure, } \\
\mathrm{MPa}\end{array}$ & $\begin{array}{c}\text { Spraying } \\
\text { distance, } \\
\mathrm{mm}\end{array}$ \\
\hline $\begin{array}{l}\text { Serial metallizing torch EM-14 (Barnaul Hard- } \\
\text { ware and Mechanical Plant, RF) (Figure 3, } a \text { ) }\end{array}$ & $32-34$ & $200-250$ & $120-130$ & - & $0.6-0.7$ & $150-180$ \\
\hline $\begin{array}{l}\text { Modernized torch EM-14M with two profiled } \\
\text { nozzles (Figure 3, } b \text { ) }\end{array}$ & $32-34$ & $200-250$ & $120-130$ & - & $0.6-0.7$ & $150-180$ \\
\hline $\begin{array}{l}\text { Supersonic torch PLAZER15-SA-EM for unit } \\
\text { PLAZER15-SA (Figure 1) }\end{array}$ & $34-36$ & $160-180$ & 90 & 4.0 & 0.6 & $70-130$ \\
\hline
\end{tabular}

Notes. 1. Diameter of flux-cored wires is $1.8 \mathrm{~mm}$. 2. Flux-cored wires of the systems based on Fe-B (with powder filling based on ferroboron) and $\mathrm{Fe}-\mathrm{Cr}-\mathrm{C}$ (based on carbon ferrochromium) were used for spraying.

Table 2. Effect of types of electric arc metallizing torches on characteristics of process of spraying of coatings from flux-cored wire of $\mathrm{Fe}-\mathrm{B}$ and $\mathrm{Fe}-\mathrm{Cr}-\mathrm{C}$ system

\begin{tabular}{|l|c|c|c|c|}
\hline \multicolumn{1}{|c|}{ Type of electric arc equipment } & $\begin{array}{c}\text { Velocity } \\
\text { of particles } \\
\text { being sprayed } v, \\
\mathrm{~m} / \mathrm{s} \text {, at } 50 \mathrm{~mm} \\
\text { distance }\end{array}$ & $\begin{array}{c}\text { Average } \\
\text { size of particle } \\
\text { being } \\
\text { sprayed } d, \mu \mathrm{m}\end{array}$ & $\begin{array}{c}\text { Size of spraying } \\
\text { spot } B_{\mathrm{l}} \text {, mm, } \\
\text { at } 65 \mathrm{~mm} \\
\text { distance }\end{array}$ & $\begin{array}{c}\text { Content } \\
\text { of oxygen } \\
\text { in the coating, } \\
\text { wt.\% }\end{array}$ \\
\hline Serial metallizing torch EM-14 & $30-80$ & $150-180$ & $45-55$ & $1.8-2.5$ \\
\hline Modernized torch EM-14M with two profiled nozzles & $100-160$ & $80-120$ & $30-40$ & $0.73-1$ \\
\hline Supersonic torch PLAZER15-SA-EM for unit PLAZER15-SA & $370-400$ & $40-90$ & $20-30$ & $0.50-0.65$ \\
\hline
\end{tabular}

gases are added to air being sprayed. The perspectives of application of such air-gas mixtures as a spraying gas can be estimated by analysis of material oxidation in a zone of its dispersion. This is the zone where the most active interaction of metal with gases takes place due to high temperatures (6000-10000 K). A quality analysis of particles' oxidation can be obtained based on the results of thermodynamic equilibrium calculation of material-gas medium system.

The experiments show that there is no oxidation of the particles in spraying by air-gas mixture at natural gas/air ratio of 1/8. Further increase of methane fraction in the sprayed flow is unreasonable from economy point of view. Complete protection of the metal from oxidation under real conditions is virtually impossible since the coating material oxidizes already in particle cooling from melting temperature to environment temperature. The mentioned above is experimentally proved for metallizing torch by data on content of iron oxides in the investigated system depending on natural gas concentration in the air-gas mixture.

The second condition, which promotes for reduction of oxidation of the sprayed material in supersonic flow, is reduction of time of contact of the molten particles with atmosphere due to their higher velocity.

The central and side electrodes in the metallizing torch (see Figure 1) operate under different conditions. The central electrode is melted under effect of heat from arc near-cathode (anode) area with wire heating by hot combustion products at extension length behind the guided nozzle. The side electrode is melted under the effect of heat from arc plasma and anode (cathode) potential fall. Obviously, that the side wire gets more heat and velocity of its melting is always higher than that of the central one. A current level (at supply from constant-voltage power source) is set using a central wire feed rate. The rate of side wire feed is selected in such a way that its end melting takes place on a line continuing central wire surface. This is the case for providing the minimum level of arc current and voltage pulsation, uniform and stable melting of the wires, the narrowest range of melt dispersion and the smallest metal flow expansion angle. Such a mode of operation of supersonic metallizing torch on combustible products is an optimum one.

The comparative investigations of the process of supersonic spraying with the processes of electric arc spraying at subsonic regime of high-temperature jet flow (Tables 1 and 2) proved significant increase of velocity and reduction of size of particles of flux-cored wire (FCW) material being sprayed, decrease of size of spraying spot as well as significant reduction of oxidation of the material being sprayed. Serial metallizing torch EM14 (Figure 3, $a$ ) as well as the same redesigned metallizing torch (Figure 3,b) equipped with special nozzles for formation of air flow, which provides for contraction of the jet being sprayed, increase of its velocity and reduction of material oxidation, were used.

Such an improvement of virtually all technological parameters of the supersonic electric arc spraying is explained by reduction (in the case of application of such a technology) of mass of liquid metal formed at the end of FCW and, respectively, cutting of size of the sprayed material particle. Increase of dispersion 

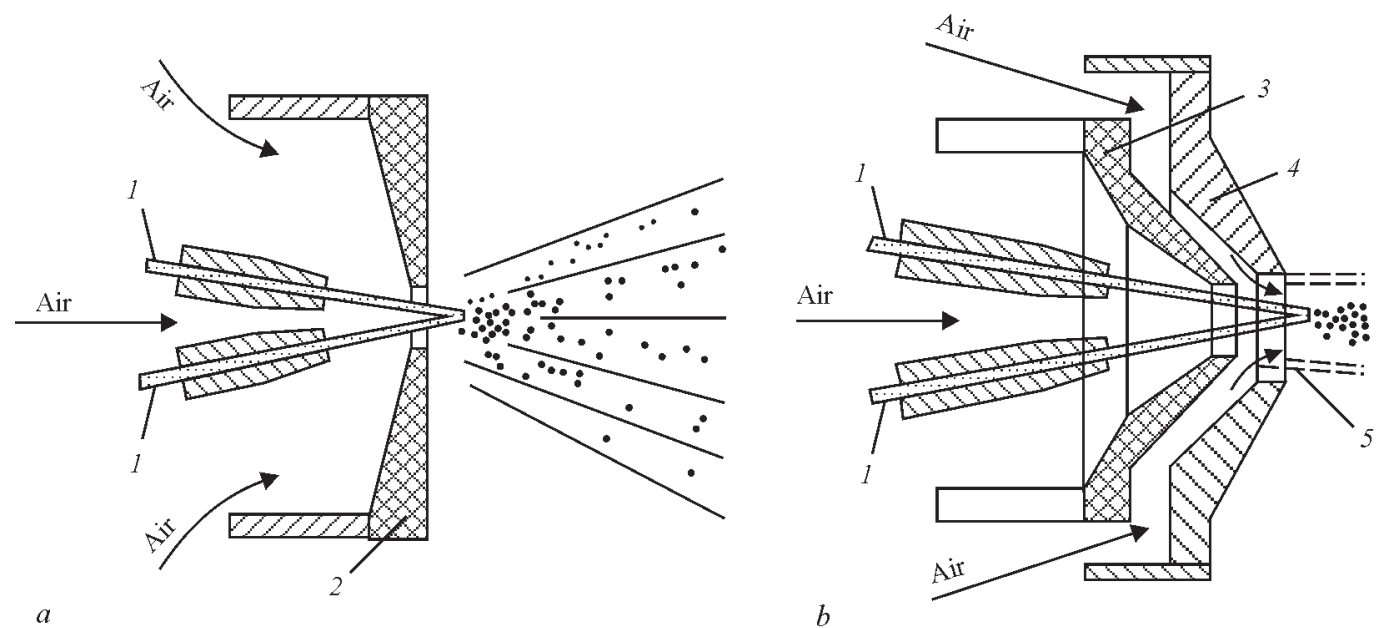

Figure 3. Basic diagram of serial EM-14 ( $a$ ) and modernized EM-14M (b) EAM torches, used for comparative investigations of spraying process and coating characteristics: 1 - flux-cored wire; 2 - standard nozzle; 3 - shaped ceramic nozzle; 4 - additional nozzle for formation of concurrent air nozzle; 5 - concurrent air flow

of the sprayed material particles results in rise of their velocity and intensifying the dynamic interaction with the base, reduction of coating porosity, decrease of size of sprayed lamellae, and respectively, rise of velocity of cooling of sprayed particles on the base and increase of amount of fast-quenched metastable structures in the coating.

Analysis of expression (1) [11] shows that the higher rate of electrode melting, frequency of release of liquid metal and reduction of mass of molten metal at the wire end is provided at the same value of welding current, density of material and geometry of FCW being sprayed due to presence of two heat sources at supersonic electric arc spraying (electric arc and high-temperature flow of hydrocarbon gas combustion products) as well as more efficient structure of the metallizing torch, from point of view of melting of FCWs:

$$
m_{1 . \mathrm{m}}^{n n}=\frac{A I_{\mathrm{a}}^{2} \gamma v_{\mathrm{e}}^{2}\left(1+2.3 \lg \frac{r_{\mathrm{e}}}{4 \delta \sin \frac{\omega}{2}}\right)\left(\frac{M}{\gamma}\right)^{2 / 3}}{12.6 f^{2}\left(1.5 T_{\mathrm{b}}-T_{\mathrm{l} . \mathrm{m}}\right) \sin ^{2}\left(\operatorname{arctg} \frac{2 v_{\mathrm{e}} \sin \omega}{f d_{\mathrm{e}}}\right)},
$$

where $I_{\mathrm{a}}$ is the arc current; $\gamma$ is the density of electrode metal; $v_{\mathrm{e}}$ is the rate of electrode melting (feed); $\omega$ is the angle between the electrodes; $M$ is the molecular weight of electrode material; $f$ is the frequency of liquid metal release; $T_{b}$ is the temperature of electrode metal boiling; $T_{1 . \mathrm{m}}$ is the temperature of liquid electrode metal; $d_{\mathrm{e}}, r_{\mathrm{e}}$ are the diameter and radius of electrodes being sprayed; $\delta$ is the thickness of shell of FCW; $A=0.005 \mathrm{~N} / \mathrm{A}^{2}$ is the coefficient.

The experimental data (see Table 2) verify the results of theoretical analysis.

Sparcely alloyed FCW based on $\mathrm{Fe}-\mathrm{Cr}-\mathrm{C}$ system was used as a material for spraying. Carbon ferro- chrome is the main component of powder core. Selection of composition of this FCW is based on further development of approaches to alloying of the FCWs for metallizing $[6,11]$. These approaches provide for such a choice of the components of powder filler promoting formation of the sprayed coating on composition close to chromium steels, containing 1-2\% C and $4-10 \% \mathrm{Cr}$ and having tendency to quenching from liquid state and, as a results, increased wear resistance. Since the coatings of friction assemblies of railway rolling stock parts operate at increased dynamic loads, they have increased requirements to cohesion strength. Therefore, the following methods were used for increase the cohesion strength of such coatings with the base in development of composition of FCWs for deposition of coatings on the indicated types of parts, taking into account the peculiarities of technology of supersonic electric arc spraying:

- increase of temperature of the particles being sprayed due to aluminothermic reactions, which are provided by means of addition of hematite and aluminum $\left(\mathrm{Fe}_{2} \mathrm{O}_{3}+\mathrm{Al}=\mathrm{Al}_{2} \mathrm{O}_{3}+\mathrm{Fe}+\mathrm{Q}\right)$ mixture. The result of such reaction is a rise of temperature of the particles being sprayed, and formation of aluminum oxide strengthening phase in the coating;

- reduction of iron oxides, forming during melting and dispergation of FCW shell and charge, by means of introduction of alumo-containing additives and foundry alloys including mish metals, with exothermal reactions;

- increase of arc temperature and reduction of size of arc column due to entering of optimum amounts of additives of alkali metal halogenides.

Rise of temperature of the particles being sprayed and increase of their dispersion is very important, particularly, when applying spraying at supersonic velocities of jet flow, since in this case the time of 


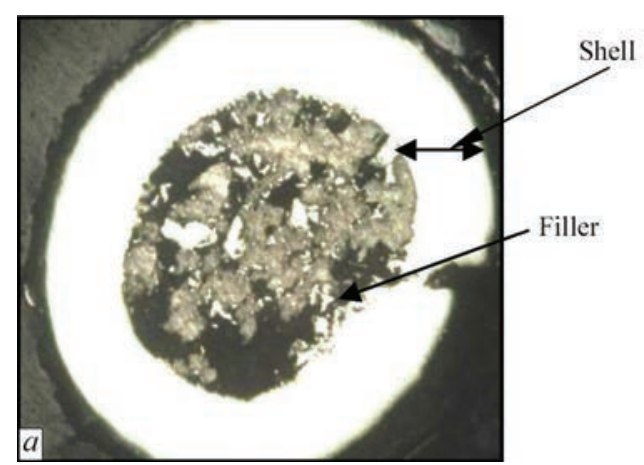

Figure 4. Microstructure of cross section of PP-AN202-S FCW ( $a$ $0.36 \mathrm{Al}, 0.2 \mathrm{Mn} ; 2-0.36 \mathrm{Fe}, 0.2 \mathrm{Cr}, 99.67 \mathrm{Al}, 0.07 \mathrm{Mn}$

holding of molten droplet at the wire end in high-temperature zone of electric arc is significantly reduced in comparison with the traditional technologies of spraying using low-velocity (subsonic) jets. Also, at that strong metallurgical bonds between the particles being sprayed and metallic base are developed due to activation of chemical interaction between them and base and receiving solid and strong oxides.

Due to the fact that different hardness indices are necessary depending on types of parts of rolling stock, a range of compositions of PP-AN202-S FCWs were developed for providing different hardness and tribotechnical characteristics. The mandatory requirement as a result of supersonic electric arc spraying of such FCW was to receive an alloy having a tendency to quenching from liquid state, and obtaining the coating on composition close to chromium steels with $1-2 \% \mathrm{C}$ and $4-10 \% \mathrm{Cr}$ containing metastable quenching structures based on oversaturated solution.

Calculation of relationship of elements' concentration in the sprayed layer and concentration of components of powder charge was carried out based on solving the system of equations [11]

$$
\begin{aligned}
& A_{a}=\frac{\eta_{a}}{100}\left(x_{1} k_{1}^{(a)}+x_{2} k_{2}^{(a)}+\ldots x_{n} k_{n}^{(a)}\right) k_{\mathrm{f}}, \\
& A_{i}=\frac{\eta_{i}}{100}\left(x_{1} k_{1}^{(i)}+x_{2} k_{2}^{(i)}+\ldots x_{n} k_{n}^{(i)}\right) k_{\mathrm{f}},
\end{aligned}
$$

where $a, \ldots i$ are the alloying elements; $\eta_{a}, \eta_{i}$ are the coefficients of transfer of these elements; $x, \ldots x_{n}$ is the fraction of materials (ferromanganese, ferrochromium, metallic aluminum etc.); $k_{1}^{(a)} \ldots k_{n}^{(a)}, k_{1}^{(i)} \ldots k_{n}^{(i)}$ is the concentration of elements in corresponding materials, being introduced into the charge of flux-cored rod; $k_{\mathrm{f}}$ is the filling coefficient $\left(k_{\mathrm{f}}=0.15-0.45\right)$.

Composition and microstructure of initial FCW of $\mathrm{Fe}-\mathrm{Cr}-\mathrm{C}$ system and coatings, produced by electric arc spraying method using subsonic and supersonic jets, were investigated. 08kp steel strip was used for manufacture of shell of this FCW. The main components of the flux-cored charge were high-carbon ferrochromium FKh900 and iron powder with

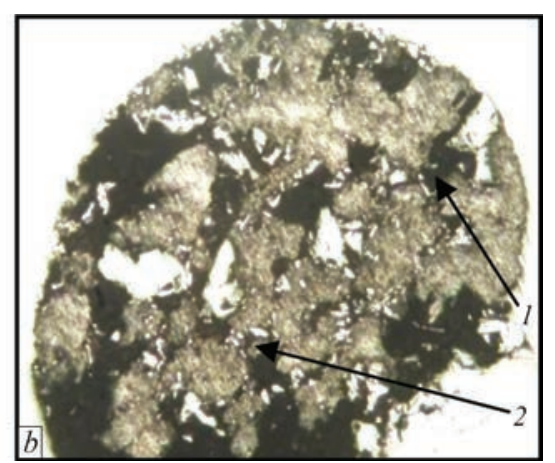

$\times 50 ; b-\times 100): 1-$ composition of particles $16.6 \mathrm{Fe}, 82.8 \mathrm{Cr}$, ferromanganese additives. PZhR5.315.28 hematite MRTU 14-14r-84 and aluminum powder PA-3s of up to $150 \mu \mathrm{m}$ particle size were used as exothermal additives. The microstructure and composition of this FCW and powder filler are shown in Figure 4.

Analysis of the results of metallographic examinations of the coatings showed that the microstructure at subsonic velocities of air flow is inhomogeneous, coarse grained, with large amount of pores and oxide inclusions. Material of the coating is overheated, oxidized, oxide interlayers contain $29-32 \%$ of oxygen, and weight fraction of oxygen in the lamellae reaches $2.5 \%$. Spherical shape particles are also observed. They due to slow flight velocity had time to cool down before collision with the surface being sprayed (Figure 5,a). The coating, made using modernized standard unit applying additional air flow and regulated expansion angle of particles' flow, is less oxidized. Weight fraction of oxygen in the lamellae and oxide interlayers makes $1.6-1.8$ and $29-30 \%$, respectively. The thickness of lamellae for these coatings is the same as in similar subsonic modes and makes $\delta=10$ $30 \mu \mathrm{m}$ (Figure $5, b$ ), coating porosity is $2-3 \%$.

At transfer to the supersonic air-gas method of metallizing, rise of air jet velocity promotes for increase of particle flow and microstructure of the received coating undergoes significant changes. Combination of small size of the particles being sprayed and their high velocities during collision with the base surface results in high velocities of cooling of their material. The particles are mainly of lamellar shape and undergo significant deformation. No inclusions of the globular particles are observed. Thin oxide interlayers are noted. The coatings on the whole thickness have uniform thin lamellar structure that indicates process stability. Thickness of the coatings, deposited at supersonic air-gas spraying, lie in $\delta=5-10 \mu \mathrm{m}$ range (Figure 5, c). Porosity of the structure reduces and makes $0.4 \%$.

The analysis of the results of X-ray spectrum microanalysis and diffractograms of the coatings 


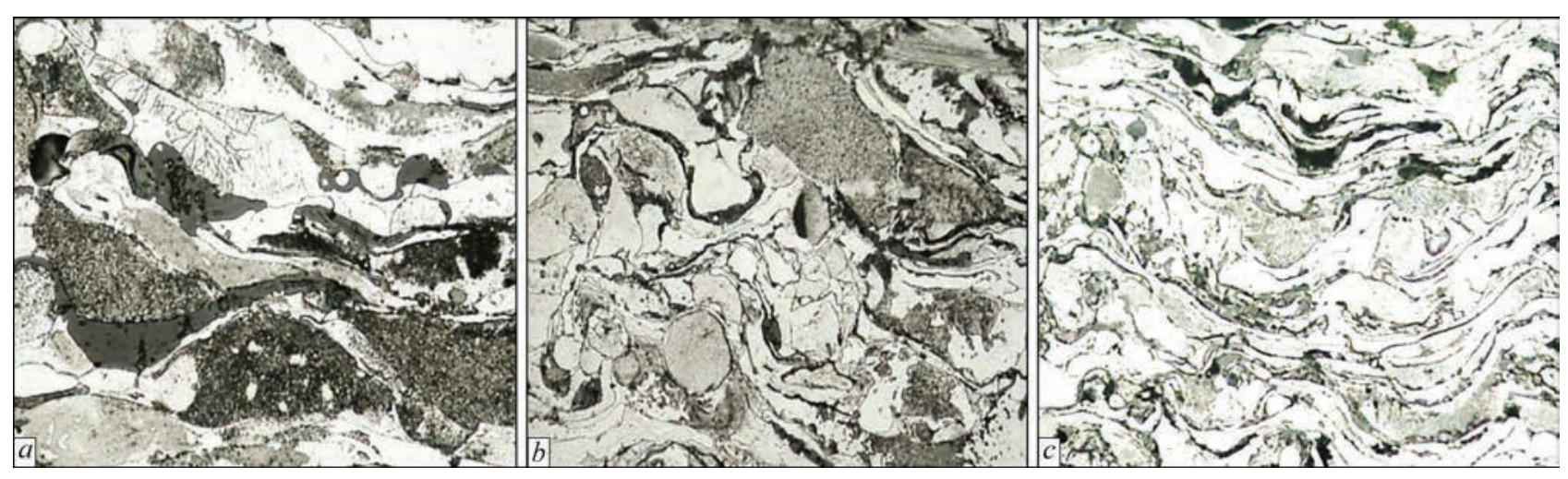

Figure 5. Microstructure $(\times 400)$ of coatings from flux-cored wire of $\mathrm{Fe}-\mathrm{Cr}-\mathrm{Al}$ system produced by spraying using serial EAM torch EM-14 (a), modernized torch EM-14M $(b)$ and supersonic torch PLAZER15-SA-EM (c)

showed that all examined coatings, produced by methods of usual subsonic EAM, modernized and supersonic EAM contain a solid solution of aluminum and chromium in $\alpha$-iron (body-centered cubic lattice with $a=0.287 \mathrm{~nm}$ ), and solid solutions of aluminum and chromium in $\gamma$-iron with face-centered cubic lattice and different content of these elements. Based on data of X-ray spectrum microanalysis, the prevailing structure in the coating at simple arc and modernized metallizing is a solid solution of chromium with aluminum in $\alpha$-iron, and in the case of supersonic EAM the main phase of the coating is $\gamma$-phase. At supersonic EAM and modernized EAM the phase constituent of $\gamma$-iron with changed parameters exists in two modifications, namely $\gamma_{1}=\mathrm{Fe}(\mathrm{Cr}, \mathrm{Al})$ with $a=0.3677 \mathrm{~nm}$ and $\gamma_{2}=\mathrm{Fe}(\mathrm{Cr}, \mathrm{Al})$ with $a=0.3633 \mathrm{~nm}[12]$.

The difference in values of parameters of $\gamma_{1}-\mathrm{Fe}$ and $\gamma_{2}$-Fe lattice indicate the different content of alloying elements. It is determined that the maximum concentration of chromium in the solid solution based on iron in the lamellae of the coatings, produced at simple and modernized spraying, makes $16.8-17.1$ and 15.0-15.4 wt.\%, respectively, under the same conditions the aluminum content is approximately from 4.0 to $6.2 \%$. Besides, in process of spraying aluminum reacts with oxygen forming $\mathrm{Al}_{2} \mathrm{O}_{3}$ inclusions, containing 35-39 wt.\% $\mathrm{Al}$ and 29-32 wt.\% O [12]. In use of supersonic jets a turbulent mode of jet flow is turned into lamellar one, that reduces air admixing and, simultaneously, increases particles' velocity due to rise of gas jet velocity. At supersonic spraying amount of chromium and aluminum, dissolved in iron, rises and the maximum concentration of chromium in the lamellae reaches 20.0-20.5 wt.\%. Solid solution of such concentration is characterized by high oxidation resistance of air oxygen. The level of oxidation of the sprayed coating is significantly reduced. The lamellae include around $1 \% \mathrm{O}$. Work [12] gives more detailed results of investigations of structure of these types of coatings.
The comparison of microhardness values of the coatings from FCWs, sprayed by different methods, shows that the microhardness of coating, produced at simple EAM, varied in 1930-4200 MPa ranges, the microhardness of coating, made on modernized unit, changes in the range from 2540 to $5100 \mathrm{MPa}$. The maximum microhardness is typical for the supersonic coatings, where the range of values lies in 3900 $6100 \mathrm{MPa}$ limits that can be related with increase of chromium content in iron-based solid solution.

The value of failure stress in coating-steel 45 base combination at normal tear, determined on «tapered pin» technology, was used in a comparative estimation of coating cohesion strength $\sigma_{\text {coh }}$ with the base. The results of testing prove the efficiency of application of the supersonic electric arc spraying technology and almost 2 times increase of the values of cohesion strength of coating to base in comparison with the traditional technology (Figure 6).

Tribotechnical tests of considered coatings were carried out under conditions with limited lubrication using disc with coating-block schemes (rider - cast iron SCh-20 and steel 40Kh, $P=10 \mathrm{MPa}, v=1 \mathrm{~m} / \mathrm{s}$, oil NS20, $30 \mathrm{drop} / \mathrm{min})$. It is determined that the technology of electric arc spraying has significant effect on intensity of wear-out of the coatings from FCW based on $\mathrm{Fe}-\mathrm{Cr}-\mathrm{C}$ of PP-AN202-S grade. A value of wear-out intensity of the coatings, deposited using supersonic electric arc spraying with the help of EAM torch PLAZER15-SA-EM, makes $3.1 \mu \mathrm{m} / \mathrm{km}$, when this index for the coatings, deposited using modernized EAM torch EM-14M, makes $4.3 \mu \mathrm{m} / \mathrm{km}$, and for serial metallizing torch EM-14 it is $7.8 \mu \mathrm{m} / \mathrm{km}$. Application of technology of the supersonic electric arc spraying allows more than 2.5 times increase of coating wear resistance. At the same time, all investigated coatings exceed EAM of steel 20, the wear values of which makes around $10 \mu \mathrm{m} / \mathrm{km}$.

Based on the technological investigations and experience of the supersonic wear resistance, the developed 


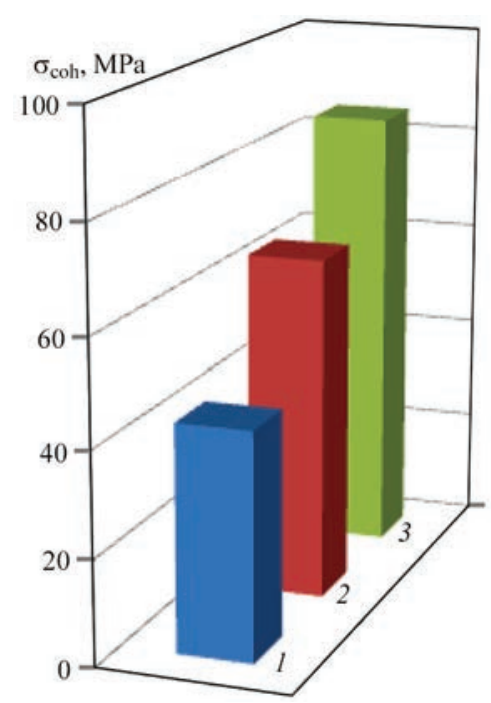

Figure 6. Cohesion strength of steel 45 base to coatings from PP-AN202-S FCW produced with serial EAM torch EM-14 (1), modernized torch EM-14M (2) and supersonic torch PLAZER15-SA-EM (3)

technology and FCW based on Fe-Cr-C of PP-AN202-S grade were used for reconstruction of the heavy-duty crankshafts of locomotive diesels 12VFE 17/24 of D1 trains of Hungarian production. Improved supersonic EAM torch PLAZER15-SA-EM (Figure 7, $a$ ) was used in 2012-2013 to modernize the process area for electric arc spraying of crankshafts of locomotive diesels 12VFE $17 / 24$ at locomotive facility in Illovaysk (Ukraine).

It is determined as a result of operation of the reconstructed locomotive crankshafts of these grades that no technical defects of the coating and shafts were registered, and service period of the reconstructed crankshaft journals is 2 times more than in new ones. It is important that the coating has a high survivability in comparison with the base metal of the crankshaft under extreme and emergency situations (stop of oil supply, presence of abrasive particles).

Also this technology became a basis for organizing a process area of supersonic electric arc spraying of axles of wheel sets of railway transport (Figure 8) at Korosten locomotive facility in 2013. It is shown that application of the developed technology and equipment for supersonic electric arc spraying of coatings on journals and seats of wheel sets of freight cars, simultaneously with application in spraying of sparcely-alloyed FCW based on Fe-Cr-C of PP-AN202-S grade allow acquiring higher surface hardness and larger depth of strengthened layer in comparison with the requirements of reference documents.

In the conclusion it should be noted:

1. Improvement of quality of wear-resistant coatings for critical parts of rolling stock by means of application of the developed technology of supersonic electric arc spraying was received due to the following new engineering solutions:

- application of improved design supersonic EAM torch PLASER15-SA-EM realizing hybrid process combining electric arc spraying with supersonic gas spraying at formation of single supersonic high-temperature gas flow and blowing of the stabilized electric arc with natural gas hot combustion products;

- application of special FCW based on $\mathrm{Fe}-\mathrm{Cr}-\mathrm{C}$ of PP-AN202-S grade developed for the supersonic electric arc spraying having alloying system providing formation of the sprayed coating close on composition to chromium steels containing $1-2 \% \mathrm{C}$ and $4-10 \% \mathrm{Cr}$, which are characterized by a tendency to quenching from liquid state. At that given FCWs include the additives realizing a series of effects and providing rise of cohesion strength of sprayed coatings to the base, namely:

- increase of temperature of the particles being sprayed due to alumothermal reactions, which are provided by means of addition of hematite and aluminum mixture $\left(\mathrm{Fe}_{2} \mathrm{O}_{3}+\mathrm{Al}=\mathrm{Al}_{2} \mathrm{O}_{3}+\mathrm{Fe}+\mathrm{Q}\right)$. A result of such a reaction is increase of temperature of sprayed particles, and formation of oxide aluminum strengthening phase in the coating;

- reduction of iron oxides, forming in process of melting and dispersion of shell and charge of the FCW

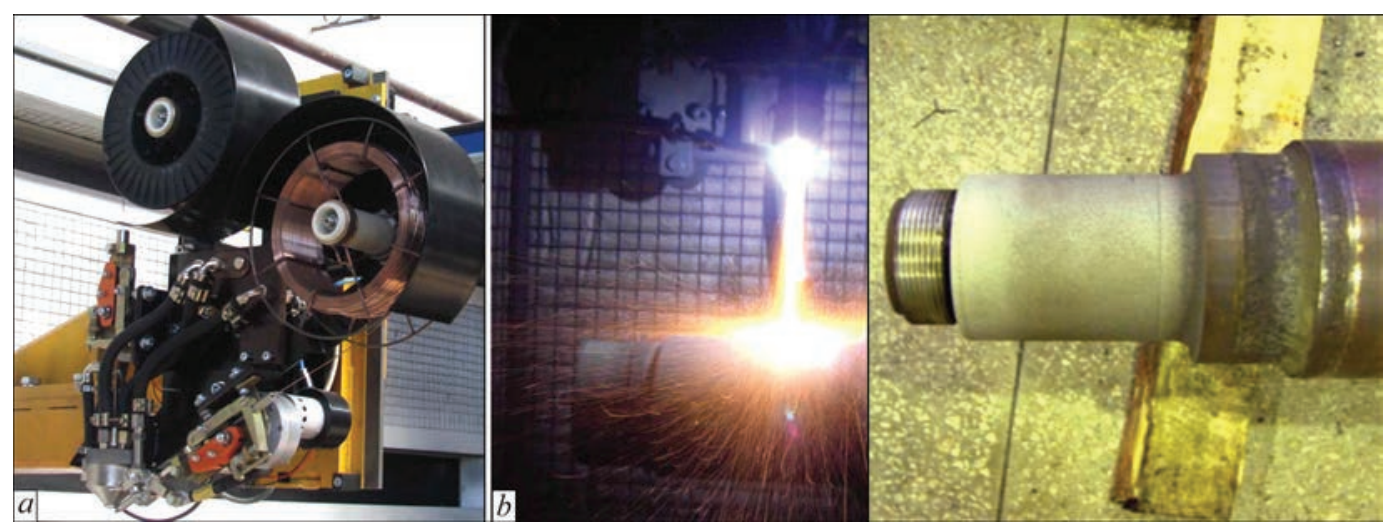

Figure 7. Appearance of block of machine supersonic metallizing torch PLAZER15-SA-EM of PLAZER15-SA unit (a), and process of spraying of wear-resistant coating from $\mathrm{Fe}-\mathrm{Cr}-\mathrm{C}$-based $\mathrm{FCW}$ on on axle journals of railway transport wheel set $(b)$ 


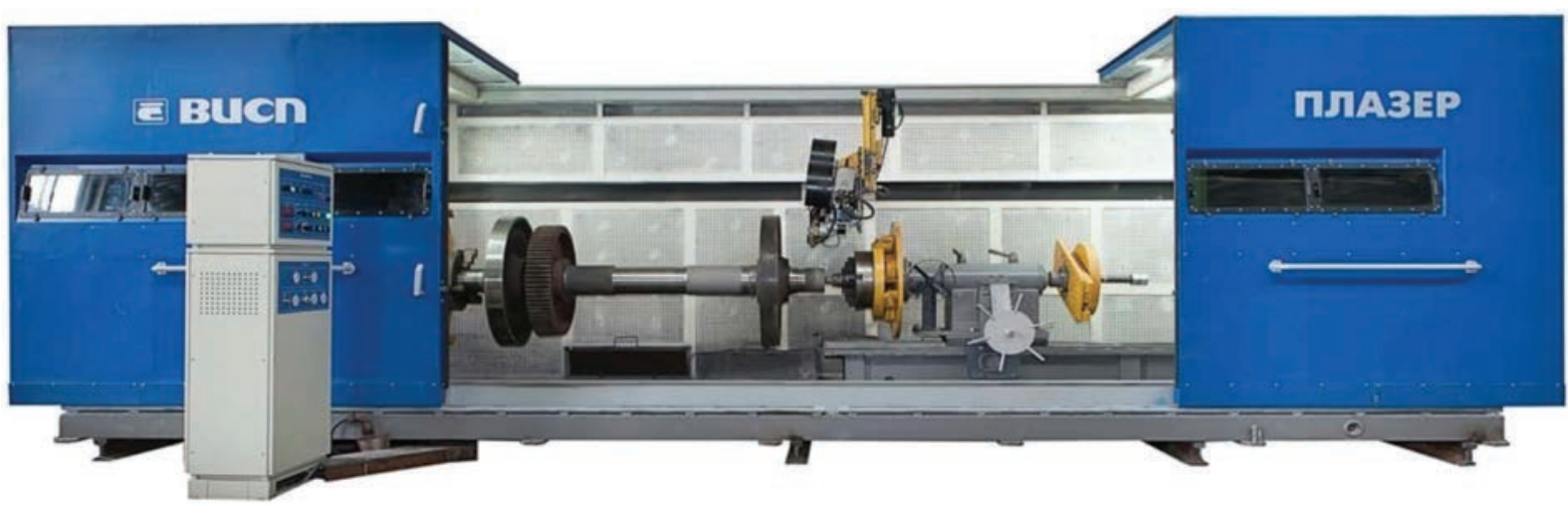

Figure 8. Appearance of engineering complex for supersonic spraying of wear-resistant coatings on axle journals of wheel sets at Korosten locomotive facility (Ukraine)

by means of entering aluminum-containing additives and foundry alloys with mishmetals and exothermal reactions;

- increase of arc temperature and reduction of size of arc column due to introduction of optimum amount of additives of alkali metals halogenides.

2 . The coatings produced using developed technology of supersonic electric arc spraying applying FCW based on Fe-Cr-C system of PP-AN202-S grade have a structure with austenite content up to $80 \mathrm{wt} . \%$. Coating strengthening is provided by formation of the oversaturated solid solution of iron with increased content of chromium to $20.5 \mathrm{wt} . \%$ and aluminum to $6.2 \mathrm{wt} . \%$.

Microhardness of the coating is approximately 30 $50 \%$ higher than the microhardness of the electric arc coatings from the same wire, produced using traditional subsonic technology, oxidation of the material being sprayed is 2-3 times reduced, and porosity decreases 3-5 times. Cohesion strength of steel coating with steel base rises from $25-30$ to $80 \mathrm{MPa}$ in comparison with application of serial metallizing torch, coating porosity reduces from $15-20$ to $0.5-3.0 \%$, material oxidation drops 2 times. Also, the technology of supersonic electric arc spraying, in comparison with traditional EAM methods, allows increasing wear resistance of the coatings more than 2.5 times.

3. Developed technology, equipment and consumables were used in order to increase the quality of the coatings for reconstruction of the critical parts of railway stock at modernizing the process area for electric arc spraying of crank shafts of locomotive diesels 12VFE 17/24 at Illovaysk locomotive facility in 2012-2013 as well as during organizing of the process area for supersonic electric arc spraying of wheel set axles of railway transport at Korosten locomotive facility in 2013.
The work was carried out under support of Chinese Program of Foreign Experts No. WQ20124400119, Guangdong Innovative Research Team Program No. 201101C014901263, Project of Guangdong Provincial Key Laboratory No. 2012A061400011, China.

1. Kuzmin, V.P., Berdin, M.M., Kuleshov, E.S. et al. (2002) Reconditioning of axle necks of wheel pairs by surfacing. Zheleznodoroznhy Transport, 1, 46-49.

2. Kuzmin, V.P. (2001) Reconditioning of axle necks of car wheel pairs by arc spraying. Vestnik VNIIZhT, 1, 46.

3. Korzhik, V.N., Krivtsun, I.V., Petrov, S.V. et al. (2009) New technology PLAZER for reconditioning of railway parts. Remont, Vosstanovlenie, Modernizatsiya, 1, 20-22.

4. Korzhik, V.N., Kharlamov, M.Yu., Petrov, S.V. et al. (2001) Technology and equipment for reconditioning of railway transport critical parts by plasma-arc spraying. Vestnik VostochnoukrNU, 14, 76-84.

5. Zelenin, V.I., Kavunenko, P.V., Tisenkov, V.V. et al. (2009) Application of plasma-arc metallization for restoration of wheel pairs. The Paton Welding J., 12, 28-31.

6. Pokhmursky, V.I., Student, M.M., Dovgunyk, V.M. et al. (2003) Structure and tribotechnical characteristics of coatings produced by electric arc metallizing using flux-cored wires. Ibid., 8, 12-16.

7. Borisov, Yu.S., Petrov, S.V. (1995) Application of supersonic jets in thermal spraying technology. Avtomatich. Svarka, 1, 41-44.

8. Frolov, V.A., Poklad, V.A., Ryabenko, B.V. et al. (2006) Technological specifics of methods of supersonic thermal spraying (Review). Svarochn. Proizvodstvo, 11, 38-47.

9. Petrov, S.V., Karp, I.N. (1993) Plasma air spraying. Kiev: Naukova Dumka.

10. Petrov, S.V., Karp, I.N. (2011) Unit of supersonic arc spraying PLAZER15-SA. Svarshchik, 1, 17-21.

11. Royanov, V.A. Theoretical principles of development and commercialization of sparcely-alloyed flux-cored wires for arc spraying of wear-resistant coatings with improved operational properties: Syn. of Thesis for Dr. of Techn. Sci. Degree. Minsk: BPI.

12. Korzhik, V.N., Borisova, A.L., Gordan, G.N. et al. (2014) Peculiarities of structure of coatings of $\mathrm{Fe}-\mathrm{Cr}-\mathrm{Al}$ system fluxcored wire produced under conditions of supersonic electric arc metallization. The Paton Welding J., 2, 31-36. 